www.jmscr.igmpublication.org

Impact Factor (SJIF): 6.379

Index Copernicus Value: 79.54

ISSN (e)-2347-176x ISSN (p) 2455-0450

crossrefDOI: https://dx.doi.org/10.18535/jmscr/v6i8.122

Journal Of Medical Science And Clinical Research

\title{
A study on the cardiovascular comorbidities in COPD patients
}

\section{Authors}

\section{V.P.Youmash ${ }^{1}$, A.Ganesh Raja ${ }^{2 *}$, Shanmugasundaram ${ }^{3}$}

${ }^{1}$ Assistant Professor, Dept. of General Medicine, Govt KAPV Medical College Trichirapalli

${ }^{2}$ Assistant Professor, Dept. of General Medicine, Govt KAPV Medical College Trichirapalli

${ }^{3}$ Post graduate student, Dept of Medicine, Kanyakumari Govt Medical College

*Corresponding Author

Dr A.Ganesh Raja

Assistant Professor, Dept. of General Medicine, Govt KAPV Medical College, Trichirapalli, India

\begin{abstract}
Background: $C O P D$, which was once considered as a disease of lungs is now being considered as a part of systemic disease caused by smoking in which the lungs become predominantly affected. COPD results in chronic hypoxemia which causes pulmonary vasoconstriction. This results in pulmonary hypertension in the long run which causes corpulmonale. The main of this study is to see whether such COPD patients are at risk of developing cardiovascular diseases and also the others cardiovascular abnormalities encountered in COPD patients since both share the common risk factor. Factors that may confound in our results like patients suffering from diabetes, hypertension are excluded from our study.

Materials and Methods: This is a prospective study, conducted by Department of General Medicine, Kanyakumari Government Medical College. The study period was from Jan 2016 to Jan 17 which included 100 COPD patients. Informed consent obtained from the patients regarding the study.

Observation and Results: It is very clear from our study that COPD patients are at increased risk of cardiovascular comorbidities, especially those who are smokers and smoke for a longer period. Also it is clear from our study that the Left Ventricular Ejection Fraction (LVEF) reduced statistically significantly even in the absence of other conventional risk factors or coronary artery diseases like Type 2 Diabetes Mellitus, Systemic Hypertension etc. COPD patients were also found to be having abnormal ECG patterns in the form of Left bundle branch block ( $L B B B)$, Left anterior hemiblock (LAHB), Right bundle branch block (RBBB). Women who accounted for $19 \%$ of the study population were also found to at increased comorbidities in the form of conduction abnormalities, reduced ejection fraction even though they are non smokers.
\end{abstract}

\section{Introduction}

COPD is a broad spectrum of disease produced mainly as a result of smoking, though it is also seen in non smokers. The spectrum includes emphysema, chronic bronchitis and small airway reactive disease. It was long thought that lungs are the main target in COPD, recent studies shows that other organs especially cardiovascular system can also get affected since the etiological factor is the same. Also the management of COPD mainly involves drugs that cause tachycardia as a side effect. Also the COPD patients are found to have dyslipidaemias which adds fuel to the fire. 
COPD is one of the obstructive lung disease. This disease is classified into four stages as per Global Initiative for Chronic obstructive lung disease based on FEV1 values. Severity of symptoms and mortality increases as we move from stage I to stage IV. Cessation of smoking is the mainstay of treatment. Bronchodilators like beta agonists and theophylline are used for symptomatic relief. Acute exacerbations are common during the course of disease which are mostly infective in origin. Hemophilus influenza, Moraxella catarrhalis are the common organisms that causes exacerbations. Vaccinations against pneumococcal and hemophilus are used in COPD patient to reduce morbidity. The chronic hypoxemia seen in COPD patients places strain on the right heart. Hence in the long run corpulmonale develops. The aim of this study is to find out other cardiovascular comorbidities that may develop in such COPD patients.

\section{Materials and Methods}

In our study, we tried to find out the cardiovascular comorbidities in COPD patients who are neither hypertensives nor diabetics or corpulmonale patients. About 100 patients confirmed and classified into various stages as per GOLD criteria were selected and were followed up for one year to detect the cardiovascular abnormalities that they develop over this observational period using ECG and ECHO parameters.

\section{Results}

COPD and ECG axis change

\begin{tabular}{|l|c|c|c|}
\hline & \multicolumn{2}{|c|}{ AXIS } & \\
\hline COPD_STG & Left & Right & Total \\
\hline 1 & 2 & 0 & 2 \\
\hline 2 & 6 & 13 & 19 \\
\hline 3 & 2 & 9 & 11 \\
\hline 4 & 1 & 8 & 9 \\
\hline
\end{tabular}

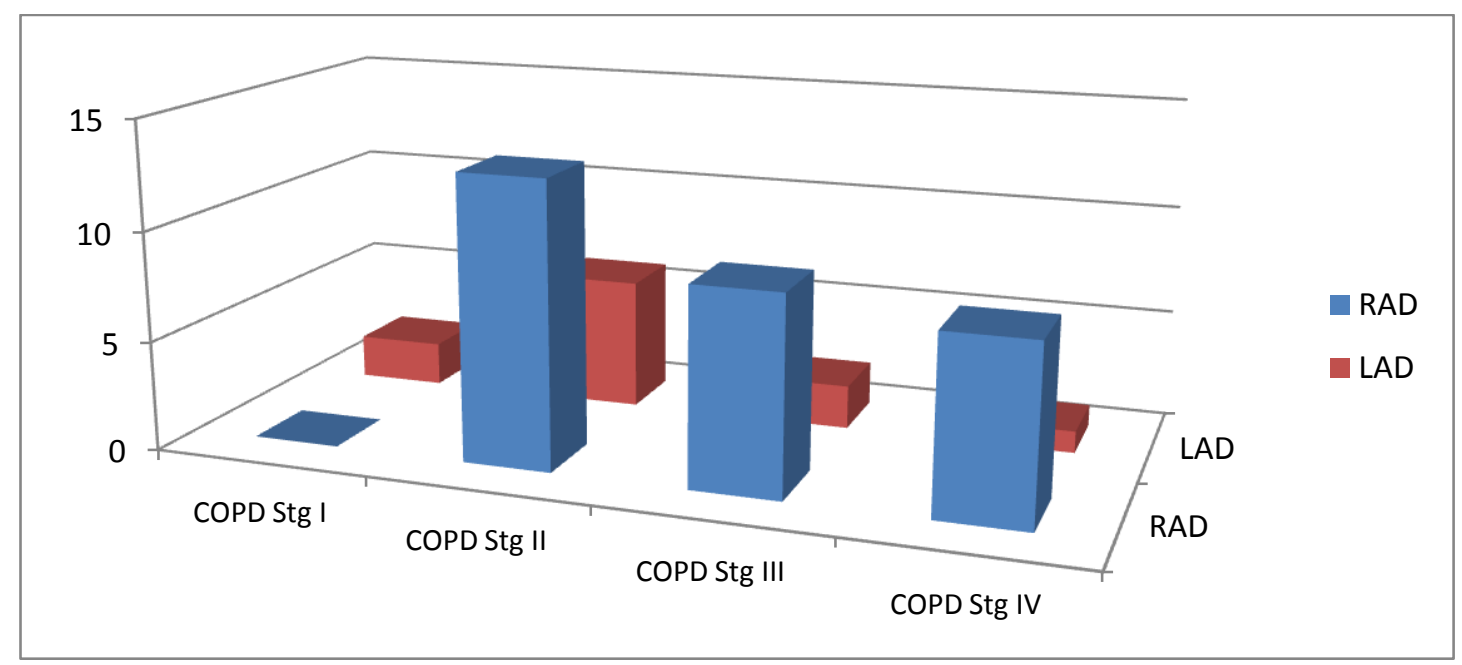

Ejection fraction in our study group

\begin{tabular}{|c|c|c|}
\hline \multirow{4}{*}{ COPD Stage I } & above 60 & 40 \\
\hline & $50-59$ & 2 \\
\hline & $40-49$ & $\mathbf{O}$ \\
\hline & $30-39$ & $\mathbf{O}$ \\
\hline \multirow{4}{*}{ COPD Stage } & above 60 & 6 \\
\hline & $50-59$ & 26 \\
\hline & $40-49$ & 3 \\
\hline & $30-39$ & $\mathbf{O}$ \\
\hline & above 60 & $\mathbf{O}$ \\
\hline Stage III & $50-59$ & $\mathbf{O}$ \\
\hline COPD & $40-49$ & 11 \\
\hline & $30-39$ & 2 \\
\hline \multirow{4}{*}{ COPD Stage IV } & above 60 & $\mathbf{O}$ \\
\hline & $50-59$ & $\mathbf{O}$ \\
\hline & $40-49$ & $\mathbf{1}$ \\
\hline & $30-39$ & 9 \\
\hline
\end{tabular}




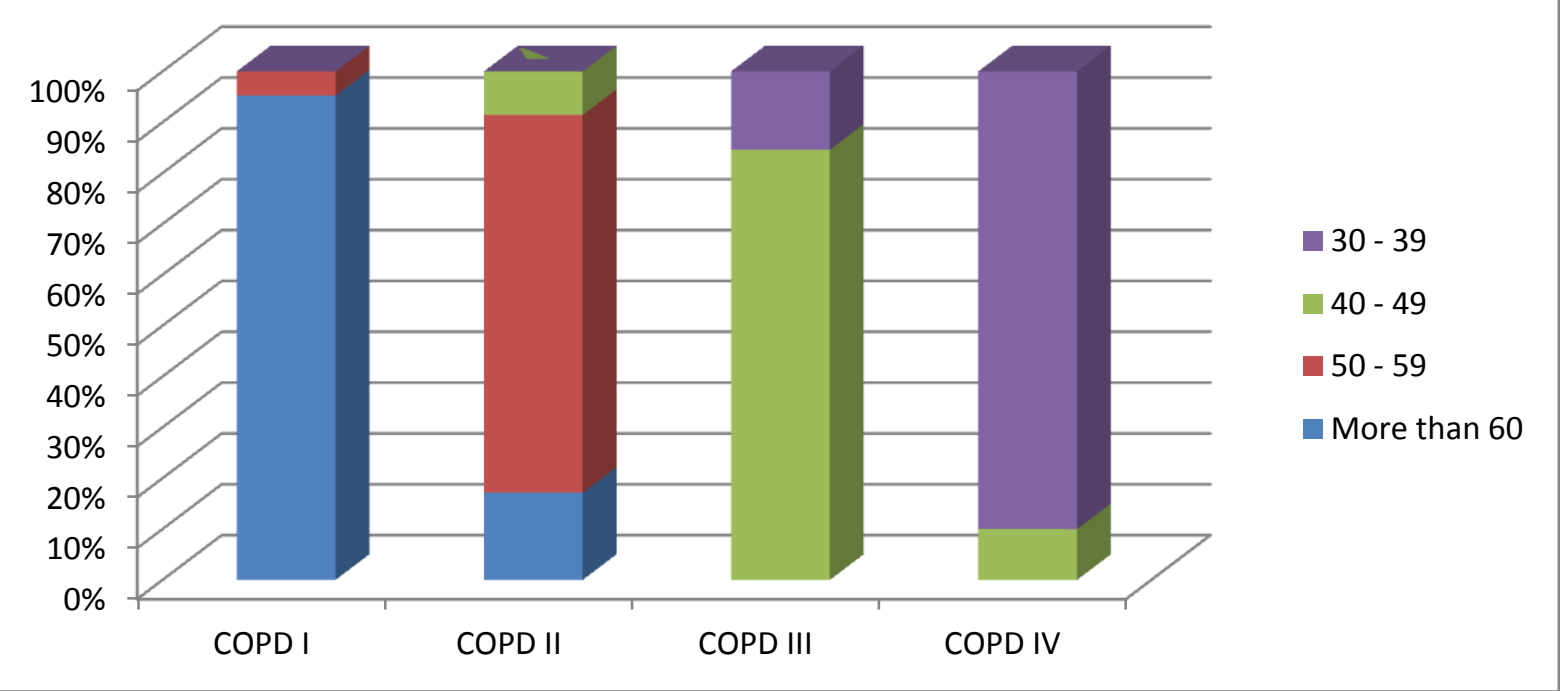

\section{Sex distribution}

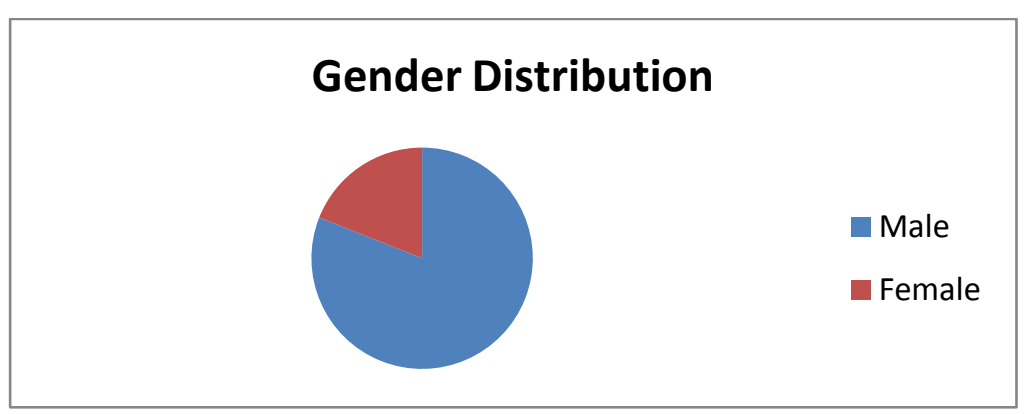

\section{Conclusion}

Out of the 100 COPD patients enrolled in our study, 19 were female and non smokers. Majority were male smokers and all are found to be having some form of cardiovascular comorbidities. Hence it clearly tells us that periodic screening of COPD patients, particularly along with PFTs, will help us in addressing the comorbidities in the earlier stages itself.

Patients who were found to be having corpulmonale were not included in our study. Hence if such patients are included, it will surely indicate that the COPD patients are at increased risk of cardiovascular diseases even in the absence of conventional cardiovascular high risk factors. Early interventions in the form of quitting smoke, active and healthy lifestyle could prevent these cardiovascular comorbidities. Also intense education programme to the adolescent people about the harmful effects on the overall health system could improve the incidence of new COPD patients.

\section{References}

1. Suissa S, Dell'Aniello S, Ernst P. Longterm natural history of chronic obstructive pulmonary disease: severe exacerbations and mortality. Thorax. 2012;67:957-963.

2. Patel AR, Hurst JR (2011) Extrapulmonary comorbidities in chronic obstructive pulmonary disease: state of the art. Expert Rev Respir Med 5: 647-662. doi: 10.1586/ers.11.62

3. Rasmussen $\mathrm{T}$, Kober $\mathrm{L}$, Pedersen $\mathrm{JH}$, Dirksen A, Thomsen LH, Stender S, et al. (2013) Relationship between chronic obstructive pulmonary disease and subclinical coronary artery disease in longterm smokers.Eur Heart J Cardiovasc Imaging 14: 1159-1166. doi: 10.1093/ehjci/jet057

4. de Lucas-Ramos P, Izquierdo-Alonso JL, Rodriguez-Gonzalez Moro JM, BellonCano JM, Ancochea-Bermudez J, CalleRubio M, et al. (2008) Cardiovascular risk 
factors in chronic obstructive pulmonary disease: results of the ARCE study. Arch Bronconeumol 44: 233-238.

5. Clarenbach $\mathrm{CF}$, Thurnheer R, Kohler $\mathrm{M}$ (2012) Vascular dysfunction in chronic obstructive pulmonary disease: current evidence and perspectives. Expert Rev Respir Med 6: 37-43. doi: 10.1586/ers.11.82

6. Topsakal R, Kalay N, Ozdogru I, Cetinkaya Y, Oymak S, Kaya MG, et al. (2009) Effects of chronic obstructive pulmonary disease on coronary atherosclerosis. Heart Vessels 24: 164168. doi: 10.1007/s00380-008-1103-4

7. vanGestel AJ, Kohler M, Clarenbach CF (2012) Sympathetic overactivity and cardiovascular disease in patients with chronic obstructive pulmonary disease (COPD). Discov Med 14: 359-368.

8. Huiart L, Ernst P, Suissa S. Cardiovascular morbidity and mortality in COPD. Chest. 2005;128(4):2640-2646.

9. Rodriguez LA, Wallander MA, MartinMerino E, Johansson S. Heart failure, myocardial infarction, lung cancer and death in COPD patients: a UK primary care study. Respir Med. 2010;104 (11):1691-1699.

10. Murthy KJR, Sastry JG. Economic burden of chronic obstructive pulmonary disease. National Commission on Macroeconomics and Health Background Papers — Burden of Disease in India. 